\title{
Paging Materials to Maintain Quality Library Service During a Two-Year Renovation
}

\author{
Melanie J. Norton \\ Susan H. Keesee \\ Denise Mabe \\ Pedro Chavez \\ Kevin E. Lanning \\ Francesca Allegri
}

\begin{abstract}
Beginning in July 2002, the Health Sciences Library at the University of North Carolina at Chapel Hill underwent an 11 million dollar renovation. During three phases of the renovation, parts of the collection were inaccessible to patrons. In order to continue to make the library's collection available, library staff created a paging system. Patrons submitted requests for needed library materials using paper and electronic forms and library staff retrieved the requested items. The paging service was modified three times based on prior experience. Patrons were generally satisfied with the service. The renovation ended in December 2004.
\end{abstract}

Keywords. Paging, renovation, health sciences libraries, electronic forms, collection access, stacks management, library stacks move

\section{Introduction}

An 11 million dollar renovation of the Health Sciences Library (HSL) at the University of North Carolina at Chapel Hill began in July 2002 and was completed in December 2004. The library has a collection of approximately 3,000 journal titles and 316,000 monographs. It serves faculty, students, and staff in the schools of dentistry, medicine, nursing, pharmacy, and public health, as well as a 600-bed teaching hospital and the North Carolina Area Health Education Centers, the statewide program for health professional education. ${ }^{1}$ The HSL employs 60 full-time employees, has an annual budget of $\$ 6$ million, and is nationally recognized for its leadership in outreach and education services.

\footnotetext{
${ }^{1}$ Health Sciences Library University of North Carolina Chapel Hill Annual Report 2002-03.
} 
During the renovation, over 300,000 items were transferred to an off-site storage facility. The interlibrary loan department handled the retrieval of these items and that process is discussed in another article. ${ }^{2}$ Books and journals dated 1992 and later remained at the library.

As no viable options for an alternative space were available on campus, it was decided in the early stages of renovation planning to keep the library building open to the public and to maintain full services, as much as possible for the duration of the project. This meant staff and patrons endured the noise of jackhammers, drills, asbestos removal, and numerous fire alarms set off by dust. Disposable earplugs were in constant demand at the user services desk.

The Health Sciences Library was forced to limit patron access to the on-site collections three times, for several weeks during 2002, 2003, and 2004. While various floors and stacks were closed, users could request a book or journal article to be retrieved (paged) by the library staff, fondly regarded as the Golden Retrievers. No additional staff was hired for paging but student employee hours were increased to provide weekend service.

The paging service evolved, improving on experience learned from the previous round. This article will share the lessons learned by the staff and will offer practical advice for other libraries laboring through renovation or other temporary stack closures. It will focus primarily on the paging of inaccessible on-site library materials and how temporarily closed stacks need not frustrate users.

\section{Literature Review}

While numerous articles have been written on library renovation projects and services for closed stacks collections, especially rare books or archival materials, only two articles have addressed paging library materials during a renovation project. An article about collection moves during an earlier Health Sciences Library renovation does not discuss access to these collections. ${ }^{3}$ Miriam Deutch wrote an informative article on their paging experience in 1997. ${ }^{4}$ Kathleen Lance and Andrew Dorfman shared their experiences with renovation and paging. ${ }^{5}$ In both cases, however, collections and staff moved out of an existing library to temporary facilities, a very different scenario than the situation at the Health Sciences Library. The Montana State University-Bozeman Renne Library moved collections during renovation but the focus of their presentation on the subject was the planning and equipment required. ${ }^{6}$ However, summary advice from their experience complements findings stated here.

\footnotetext{
${ }^{2}$ Norton, Melanie J. and Vardaman, Adam S. (2005), “Maintaining Quality Document Delivery Service with Off-Site Storage Facilities," Journal of the Medical Library Association, 93(3): 394-397.

${ }^{3}$ Brogan, Linda L. and Lipscomb, Carolyn E. (1982), "Moving the Collections of an Academic Health Sciences Library." Bulletin of the Medical Libraries Association, 70(4): 374-279.

${ }^{4}$ Deutch, Miriam. (2001), "Paging a library collection: The Brooklyn College Library Experience," Collection Building, 20(1): 25-31.

${ }^{5}$ Lance, Kathleen and Dorfman, Andrew. (1999), “Maintaining Academic Library Services during a Renovation Project," College and Undergraduate Libraries, 6(1): 65-76.

6 Tetro, Robert and Callahan, Kathie. "Stacks Dominos: Stacks Management during Renovation or Construction," April 2002, <http://www.lib.montana.edu/ rtetro/stacksdominos/> (29 June 2005), Montana State University The Libraries.
} 


\section{Decision to Page}

Before construction, several task forces were formed. These included Collections, Communications, Facilities, Systems, Staff Morale, and Services. The five-member Services Task Force considered several options for providing materials to patrons when construction activities prevented public access to the library stacks. These options included using interlibrary loan and document suppliers for items that were temporarily inaccessible, advising patrons to plan their research around collection availability, and urging patrons to use the nearby Duke University Medical Center Library for research and study. Ultimately, the task force decided that these approaches were unsatisfactory as they did not serve all HSL patrons, were too expensive, or would greatly lower patron satisfaction. As an alternative, the task force decided to offer a paging service.

\section{Preparation for Renovation}

In March 2002, the Services Task Force began to advertise the impending changes the renovation would have on use of the six-floor library building and the collection. Signs throughout the library, e-mails, and a large message board near the library entrance were deployed.

Books dated before 1992 would be stored at an off-site facility. In preparation for the move these books were shelved together and shelf read. As each shelf was completed, caution tape was strung across the section to discourage use of materials. Beginning in May, a circulation due date of June 12 was set for all pre-1992 books to ensure they were returned and shelved before the move to off-site storage. Desk staff had a special routine posted on computers for checking out and renewing pre-1992 books. Staff referred to a standard script to explain to patrons why this was necessary and to alert them to the coming changes in service. Bound journals slated for transfer off site were identified with red dot stickers to assist the movers. Patrons often asked about the dots, providing another opportunity for library staff to explain the renovation transformation.

\section{Round One: June-July 2002}

Results: 3531 requests paged

3 weeks

\section{7 weekly average}

"I'm sorry we can't give you full access to the upper floors right now, but let me tell you what we've worked out so you can get what you need."

This was a typical explanation from user services desk staff to patrons seeking access to the collection on the library's third, fourth, and fifth floors.

Round One of the paging service was implemented while materials were being prepared for transfer off site and shifted within the library. By the end of Round One, no materials from the upper three floors were available for patron browsing, and all books and journals published after 1992 were paged.

The Services Task Force sent an e-mail to the library staff asking for volunteers to sign up as Golden Retrievers. At least one Golden Retriever was scheduled for each morning, mid-day and late-day retrieval shift. If there was a shortage of Golden Retrievers or a backlog of requests, a call for help was 
sent to all staff by e-mail. The staff responded well to both scheduled shifts and calls for extra help. A small group of staff was trained to access the e-mail account to print and then archive the requests electronically. After printing, staff took the requests to the processing area behind the service desk for the Golden Retrievers to pick up.

The Round One paging request form promised "Staff will retrieve books and journals on a regular schedule throughout the day. Materials can be picked up at the front desk 2-3 hours later. If you request materials later than two hours before the library closes, these will be available for pickup the next day." It also indicated that retrieved books and journals would be held 48 hours and suggested that patrons call the library to confirm that their material was ready for pickup. Materials requested between Friday afternoon and Sunday evening were available by noon on Monday.

Staff were instructed to fill requests for university affiliates only, retrieve up to 10 requests per day per person and accept any legible request form. During the first round, patrons had the option of submitting a request online, which was sent to a Hotmail account set up specifically for HSL paging, or filling out an identical paper form available at the user services desk. Patrons were required to fill out a separate form for each item needed. This was necessary because it was more efficient to batch requests from several patrons than to keep each patron's requests together when pulling items from the shelves.

The same request form was used for books and journals. It included patron's first and last names, phone number, e-mail address, and the book or journal's title, volume, issue/month, year, first page number, and book call number. Staff naively assumed that patrons would request only journals to which the library subscribed and would provide complete citations including the full title of journals, not the standard abbreviations. These assumptions proved false, further complicating the paging process.

\section{Step-by-Step}

Requests were batched with others submitted within the same time period, generally hourly. The process to fill a single request during Round One was:

- Patron submits a written or online request on a standard form designed by library staff.

- Staff retrieves bound journal volume or book from the upper floors.

- Staff inserts large bookmark in the item (8-1/2 × 11 paper folded in half lengthwise) with patron's last name and first initial written on the top edge.

- Staff interfiles item with interlibrary loan pickups and other books placed on hold.

- Patron picks up material within a day or two, photocopies the article or checks out the book and returns the item to the service desk.

- Staff reshelves item.

\section{Evolving Policies}

Within a week of launching the paging service, the number of pulled journal volumes exceeded the hold shelf space available behind the user services desk. Items not picked up by patrons contributed to the overcrowding. In addition, an unmanageable volume of questions about whether materials were available for pickup made it clear that desk staff could not be the gatekeepers for retrieved materials. The Services Task Force decided to move the paged journals to a self-service space. Fortunately, space was made available in the library reserve room located near the service desk. 
Requests for journals that were already waiting for someone else prompted another change. Staff began to photocopy entire articles for the first patron who requested a bound journal volume so that it could be placed on the hold shelf for a second requestor or because the item needed to be staged for the move to off-site storage. While the self-service approach prompted some patrons to mistakenly return bound items to the paging "hold" shelves after use, self-service access proved to be more labor efficient.

Despite preparing for the worst, remaining flexible, and communicating to patrons, the first round was a test of stamina. The high volume of requests and incomplete citations made it a challenge for the Golden Retrievers to "go fetch" the items within the two to three hour turnaround time noted on the request form. There were also times when the movers' work prevented staff from accessing the post1992 materials. If an item was not found, the form was returned to a "problems" file. Unfortunately, there was no space allocated on the forms to explain the problems, further slowing down the paging of these items. Paperwork from requests grew to foot high stacks of to-be-filled, done, and problems. At times, unresolved problem cases were accidentally intermingled with the requests filled. Accepting forms in both handwritten and electronic format created a data management nightmare.

Paging Round One ended when the spacious first floor user services desk was dismantled and a much smaller service desk was open for business on the fourth floor. The collection on the fourth floor included journals and books dated 1992 and later, and all microforms and videos. Only the foreign language journals were shelved on the third floor, which was not open to the public.

\section{Feedback}

Despite efforts to advertise changes in library services, there were some unhappy patrons. On the first day of paging, two clinicians were visibly upset they did not have access to what they needed. Their complaints were relayed immediately to the supervisor of information services, who alerted all staff about an exception to the two-hour (or first-in, first-out) service policy: if clinicians stated they had a clinical emergency, their requests should be pulled first by the next available Golden Retriever or by a student shelver contacted by walkie-talkie.

Staff and patrons tried to make the best of a difficult situation. While patrons were often surprised to learn they could not access the upper floors, many accepted help on how to find articles online, search the catalog for books more efficiently and use the guides and tutorials on the library's website. Many patrons learned to make the best of the paging service, submitting their requests early in the morning and picking them up at noon.

A typical patron comment received by e-mail was:

"Thank you for putting in so much time and effort helping me find the materials I needed. I really appreciate your help. Have a great day." 


\section{Round Two: August-October 2003}

Results: 6207 requests paged

6 weeks

\section{5 weekly average}

After 14 months of renovation on the lower floors, the library collection moved from its temporary location on the fourth floor to the newly-installed compact shelving in the basement. Accessibility by patrons was not permitted because of delays in getting a certificate of occupancy. In this round, the Services Task Force decided to make two major changes in the paging process: staff photocopied journal articles and patrons were notified when articles were ready for pickup or if their request could not be filled. The justification for providing free photocopies to patrons was to promote goodwill and to compensate for the inconvenience of yet another round of temporarily inaccessible material. Also, limited space on the only floor open to the public made it necessary to reduce the number of photocopiers, and staff were concerned that long queues to make copies would add insult to injury.

The service goal was to have the requested item (article or book) available for pick up within 24 hours. Requests were submitted through an electronic form available on the library's homepage and from a link in the campus library catalog.

These forms automatically went to an e-mail inbox folder shared by several of the Services Task Force members. The information technology member of the Task Force used campus e-mail resources to set up the inbox folder in his account and to give different people various levels of access to the same e-mail messages. Those sharing the folders changed a few settings in their mail so that the shared folders would be visible in their inboxes. When patrons submitted their requests, they went to the appropriate folder using the format userID+folder@server. The folder "Paging" was for designated incoming requests. Those staff with access and rights to the folders then moved requests into a "Paging Trash" folder after printing them, and this became the archive folder. Instructions on how this system works for the UNC campus are freely available (see Setting Up Shared Mail Folders at http://help.unc.edu). As an added precaution, requests were exported and parsed into a Microsoft Access database, from which data for this article were derived. Patron identification information was stripped from this archive to preserve confidentiality.

Due to the heavy volume and the time required for photocopying, the request limit was reduced from 10 to 5 per day per person. Non-affiliated users were redirected to HSL's fee-based photocopy service, or their public library's interlibrary loan service so that the HSL staff could focus on serving their primary clientele, University of North Carolina at Chapel Hill affiliated patrons.

The temporary user services desk was smaller than the original desk but served as the contact center for circulation, reference, and paging. The "pull and process" station was set up nearby and a librarian was in charge of monitoring the paging process. That librarian organized and scheduled staff to print, file, and retrieve requests and resolve paging problems. 
Step-by-Step

- Patron submits an electronic form, one for each item.

- Staff prints requests: morning, noon, 5 p.m and evening.

- Staff sorts requests by type: journal, book, or pre-1992 requests that should have been submitted to inter-library loan.

- Staff alphabetizes journal requests by titles and book requests by call number.

- Staff handwrites last names along the long side of each form for easy handling, filing, and retrieving.

- Staff verifies citations. Possible actions at this step were:

- If HSL is the only campus library that holds item, staff places request form in either the Journals or Books (to-be-pulled) folders.

- If item is available online or if journal volume or book is available at another library on campus, staff notes this and places request form in Notify file.

- If item sought is not owned by UNC Libraries, staff notes this on the request form and places it in the Notify file.

- If citation for item sought is incorrect, staff notes problem on form and places in the problems file.

- Golden Retriever removes requests from the to-be-pulled folders, retrieves volumes, collects them on a book truck and brings loaded book truck to the queue outside of the Pull \& Process Station.

- If time was available, Golden Retriever sorts pulled journal volumes by requestor's last name so that the up-to-five requests would stay together, promoting efficiency when collating multiple requests and for the notification step.

- Golden Retriever photocopies articles, keeping request form together with each article copied.

- Golden Retriever writes patron's last name along the long left edge of each stapled article for easy readability and files in the filing cabinet behind the user services desk.

- Golden Retriever staples the multiple request forms from a single requestor together, writes "DONE" and makes a diagonal mark across the front of the request form, then places request forms in the file labeled NOTIFY.

- Staff chooses which scripted electronic message to send to each requestor.

- Messages were used to (1) notify patrons that requests were ready for pick up or if they had been sent by campus mail or (2) provide patrons alternate ways to obtain materials such as online, from another campus library or through interlibrary loan.

- Staff places items that have been photocopied on sorting shelves (books by call number and journals by title) located outside of the Pull \& Process Station.

- Staff reshelves items.

At first, copies of articles were filed by patron name for self-service pickup near the user services desk. To respect patrons' confidentiality and privacy, however, photocopied articles were moved to a file behind the desk serviced by library staff. Books were held behind the user services desk as well.

\section{Evolving Policies}

Library staff wrote a series of e-mail messages that were available from the user services intranet to notify patrons on the status of their requests. The standardized messages covered these scenarios: 
- Paged item(s) ready for pickup. Come to 4th floor service desk, bring a photo id and request item by your last name.

- As instructed by you, photocopied journal articles have been put in campus mail.

- Current journals are available on the 4th floor. Come to the library to read, copy, or borrow the issue for an hour.

- Article is available online full text.

- Book is checked out to another patron. We have placed a Hold on the book and you will be contacted by e-mail when it is available for you to check out.

- Item is not owned by HSL, but is available from another campus library. (Specify which one and the call number if it differs from HSL's.)

- Item is not owned by any campus library. Links provided to interlibrary loan forms.

- Item is at the bindery. Link provided to HSL's interlibrary loan form and instructions to write in notes field "journal at bindery, free interlibrary loan."

- Journal issue sought has not yet been received.

- Need more information to fill your request.

At the start of the second phase of paging, a vicious virus shut down e-mail for several days. Staff had looked forward to using the newly developed electronic forms and the standardized e-mail messages. This event was a major disappointment and handwritten requests were accepted in person or by fax for two weeks until e-mail became reliable again.

Because library staff were doing the photocopying, the accuracy of citations became critical. Recurring citation problems resulted from patrons' lack of understanding as to what constituted an issue number or a book call number. A "Problems" folder for incomplete or inaccurate citations was set up.

Throughout the workday, librarians and other skilled staff members volunteered their time to check the folder and attempt to decipher problematic citations. If the problem could not be resolved, a staff member contacted the user for more clarification. This proved to be time consuming but was done to maintain patron satisfaction and to reduce the chance of photocopying the wrong article. When a problem was resolved, the request was placed in the appropriate "To Be Pulled" file.

Early in Round Two, journal articles were copied regardless of whether the title was available electronically or at another campus library. The Services Task Force managed the photocopying volume though two actions: verifying that HSL's print collection was the only campus source of the item and greater education efforts on how to find online journal articles. Library staff sometimes sent personal email responses that included a link to online articles and step-by-step directions so patrons could develop greater self-sufficiency. Guides for finding articles online had been available on the library's website before Round Two, but patrons were alerted to them more often to reduce photocopying volume.

\section{Feedback}

At this stage of the renovation, with most of the collection inaccessible, the impact of construction was very obvious to patrons. There were many comments expressing sympathy for "living with construction," as well as shock from those for whom the "all-on-one-floor" library collection was their first realization that something was up. Some of the most frequently heard comments included:

"Having the articles already copied saves me so much time." 
"It saves me a trip to the library to have the articles copied and mailed to me."

\section{Round Three: August-December 2004}

Results: 4,714 requests paged

18 weeks

262 weekly average

When renovation of the upper floors was nearing completion, books and journals were relocated for a third and final time. Paging lasted much longer in this round because of construction related issues that again delayed getting a certificate of occupancy for these floors. Based on experiences of the first two rounds of paging, as well as experiences shared by the Biomedical Library at the University of San Diego (where staff paged items from an off-site storage facility), the Services Task Force decided not to photocopy articles in Round Three of the paging service. From the lessons learned from previous rounds, it became possible to distill information for old and new Golden Retrievers into a cheat sheet (Appendix A).

The compact shelving in the basement would hold the older books and journals returning from off-site storage. As soon as they were shelved, older books and journals were open for patron browsing and check out.

\section{Step-by-Step}

- Patron submits an electronic form, one for each item.

- Designated staff prints requests: morning, noon, 5 p.m. and evening on weekdays and at least once daily on Saturdays and Sundays.

- Staff sorts requests by floor on which an item is shelved.

- Staff alphabetizes journal requests by titles and book requests by call number.

- Staff handwrites last names along the long side of each form for easy handling, filing, and retrieving.

- Staff places requests in one of the "to be pulled" files: Journals or Books.

- Golden Retrievers pull books and journal volumes from 3rd and 4th floors three times a day: morning, 1 p.m. and evening and once each weekend day.

- Golden Retriever selects the appropriate color bookmark (the lengthwise half of an 8-1/2 11 piece of pastel-colored paper) representing the day item was retrieved. (Appendix B) All items are held for 3 days.

- Golden Retriever writes patron's last name and first initial on bookmark and places in each corresponding book or journal retrieved.

- Golden Retriever interfiles item by patron's last name on the "Paging Pick Up" shelves.

- Golden Retriever files completed request forms in "Done" files.

- If an item is not found, a probable cause is checked on the request form or a short note written to explain problem. Request form is placed in "Problems" file.

- Patron picks up item and either makes photocopies or checks it out.

- Staff scans the bookmark colors on Paging Pick Up shelves daily and removes items that have been held on shelf for four days.

- Staff reshelves item. 


\section{Evolving Policies}

The exclusive use of on-line requests continued in Round Three (see Figure 1) but simpler forms required only journal title, year, issue/month and volume or book title, author, call number and publication year (Appendix $\mathrm{C}$ ). The electronic forms also became more sophisticated, generating an automatic response when a patron requested an item they could access directly (i.e., without paging). The revised request form noted that patrons would be contacted only when requests could not be filled in 24 hours. This streamlined the process, though it initially caused some confusion among patrons used to being notified when requested materials were ready for pickup. Color-coded bookmarks created by this round's coordinator facilitated the reshelving process. It was decided that paged items would remain on the paging pick up shelves for four days instead of three to better accommodate users' needs and schedule demand.

\section{Feedback}

Patrons started commenting positively on the newly renovated building and were anxious to get to the shelves themselves. They appreciated the paging service and some expressed wishes that it continues! 


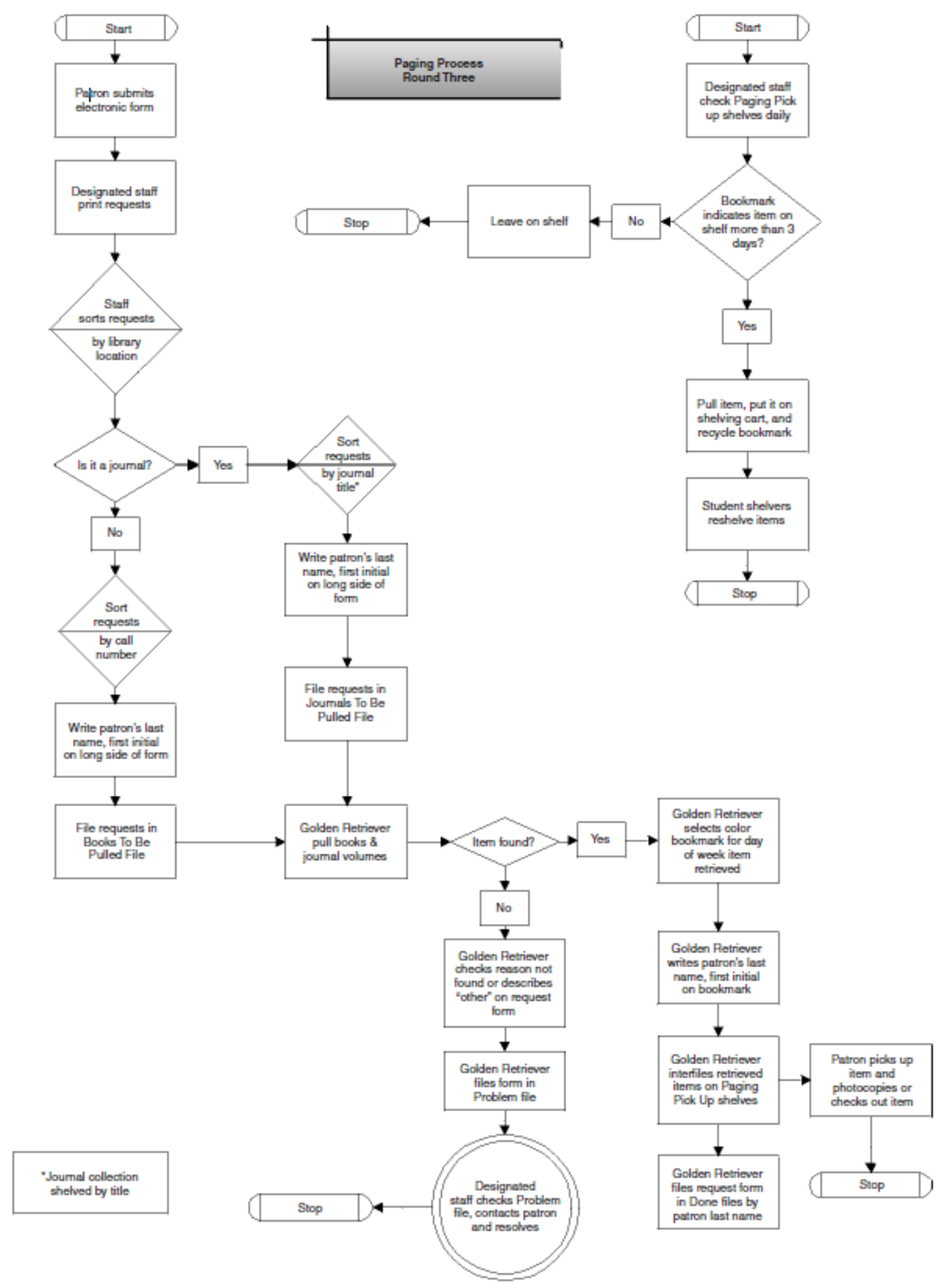

FIGURE 1 


\section{Data Analysis}

Data analysis was hampered by lack of a plan for this before the project began. Despite this, some observations were made that can be useful for service planning.

- Journal article requests for all three rounds of paging represented approximately 80 to 90 percent of all requests. These data are indicative of the environment: a health sciences library at a large research university.

- The highest numbers of paging requests occurred between Mondays and Wednesdays, tapering off through the weekend.

- The number of requests per week averaged between 1000 and 1200, until the last round when more items became available to patrons.

- At the end of each week, completed request forms were counted; statistics were compiled and reported to the entire library staff by the Services Task Force Coordinator.

\section{Recommendations to Others}

Each successive phase of the paging service incorporated lessons learned from experience, patron behavior, and patron comments. Recommendations to those developing a paging service are summarized here.

\section{Public Service}

- Allow patrons access to materials whenever possible. Interruptions to staff working on inaccessible collections are offset by patron satisfaction and less paging for volunteer staff.

- Enforce request limits gently. A kind e-mail or phone call reminder of the number of requests per day or other limits easily took care of noncompliance.

- Be flexible. Exceptions were always made such as recalling runs of journals from storage for class assignments or historical research.

- Decide to copy articles based on budget (loss of photocopy income) and staff resources. Copying versus pulling materials for patrons did not affect service satisfaction.

\section{Communications}

- Advertise and communicate with patrons using library liaisons, Websites, client listservs, a list of local document suppliers, the library advisory committee, and links to request forms on online library catalog pages. When users understand the renovation issues and services available, there are fewer complaints. When the link to request forms was taken off the top of the library's home page, complaints began immediately. Obvious links to forms worked better, e.g., "Get a Book" vs. "Request Form for Materials before 1992."

- Standardize, document, and share. Limiting methods for placing requests to online only, using standardized e-mail messages and blind copying multiple recipients, setting times of day to print requests, limiting delivery methods to pick up only, and similar standardization enabled staff to quickly handle a larger volume of requests. Document procedures and share them with the appropriate people. If this were to become a permanent service, some decisions would be reexamined. 
- Look for opportunities to promote other services. A plug for HSL's fee-based copy service was included in the online request acknowledgement message and on bookmarks placed in materials patrons picked up. To help collection browsers, staff demonstrated call number searches, table of contents services, and the online new bookshelf service.

- Plan in advance what data will be desired and/or requested for annual reports and project documentation. If using paper forms, plan how to collect data and integrate it with data collected electronically. Plan how to collect and use patron feedback. Make the suggestion box very visible and promote an online suggestion box. At meetings, ask staff to find out what patrons are saying or where there are problems. Consider adding a comment field to request forms but only if there is time to read and respond to patrons.

- If information technology developers are available, creating a database with a front end request form can enable data collection and reporting along the way.

\section{Staffing}

- Charge a group similar to the Services Task Force to plan, monitor, refine, and oversee the paging service. These staff share core tasks such as improving processes, printing requests, communicating to staff and patrons, collecting and reporting data, and ensuring service quality.

- Assign a coordinator to monitor the daily details of the paging service. Use the same coordinator in successive rounds, if possible. This is efficient and reduces chances of repeating the same mistakes. Staff, who are working for this service in addition to their usual workload, need someone with answers, who can watch for errors and glitches in the process, and can consult with others to fix problems when needed. The coordinator keeps on top of the whole process, from beginning to end, bringing unresolved issues to the Task Force. This is almost a full-time assignment, especially if the coordinator is picking up slack in the paging schedule. A Services Task Force Member is a good choice.

- Hire extra staff, either temporary or students. Students especially responded to the challenge. They enjoyed racing against each other to see how fast they could pull and/or copy an item.

- Compartmentalize and assign tasks. Solicit and assign volunteer staff to different paging groups: Golden Retrievers, Peerless Printers, Timely Troubleshooters, and Power ProblemSolvers. This way the assigned staff could focus on one task and training is easier.

- Feed and reward helpers often and celebrate milestones. The Staff Morale Task Force supplied munchies at the processing station for volunteers. They contributed by keeping the Golden Retrievers fueled with lots of chocolate, and appreciated with bouquets of flowers. As with any project out of the ordinary, a handful of staff becomes the backbone of paging in each phase. The Services Task Force gave names to those of the Staff Morale Task Force to single out for special thanks. Statistics were published weekly via e-mail, with a thank you sent to all staff, so everyone could see how much was accomplished.

- Verify citations only if justified. Collection size and the odds the item is in the library's collection are determining factors. Re-shelving needs to be kept up-to-date during paging.

\section{Forms}

- Make the forms do the work. Electronic forms are easy to sort prior to printing and to search for a patron's request that failed to get filled. Another use of electronic sorting was to check on whether a request was pending or printed (in process). Sorting also helped find and contact 
patrons exceeding service limits. Filing the completed paper requests by patron's name also helped when tracking down answers to questions.

- Design online forms to generate an instructional message. If the patron put in a publication year that was for a part of the collection not being paged, they would be instructed that this item was available on the shelf. A link to an interlibrary loan form was provided when an entered publication year was for an item in off-site storage.

- Some fields of information were required and some field names were in bold type and in larger font to aid the staff pulling materials.

- Use separate forms for books and journals to create less confusion and errors for staff and for Golden Retrievers. If fax and paper requests are to be accepted, plan how to integrate these into the work and data collection flow.

- Include a minimal, most frequently encountered checklist of problems on the form for the staff doing the paging. An "Other" option will suffice for the rest.

- Establish a small processing station for incoming requests, instructions, supplies, and files. This is a good place to highlight changes in processes and policies that volunteer staff need to know about as paging proceeds.

\section{Conclusion}

The renovation of the Health Sciences Library was completed in December 2004, and all materials in the collection were back on site by January 2005. Despite more than two years of disruption, library staff received few complaints about the paging service and access to the collections during this time. Effective planning by the Services Task Force and teamwork by the entire staff minimized inconvenience to users as well as library staff. As stated in an article by Nelson/Frantz, "if operations are performed satisfactorily, the wall surrounding the collection becomes invisible to the user." ${ }^{7}$ This is exactly what the Health Sciences Library at UNC-Chapel Hill achieved.

Received: 07/25/05

Revised: 09/12/05

Accepted: 09/13/05

Melanie J. Norton (E-mail: Melanie_norton@unc.edu) is Interlibrary Loan Coordinator; Susan H. Keesee (E-mail: shk@unc.edu) is User Services Librarian; Denise Mabe (E-mail: Denise_mabe@unc.edu) is User Services Center Operations Manager; Pedro Chavez (E-mail: pchavez@unc.edu) is Support Analyst; Francesca Allegri (E-mail: allegri@unc.edu) is Head of User Services, all at the Health Sciences Library Campus Box 7585, University of North Carolina at Chapel Hill, NC 27599-7585. Kevin E. Lanning (E-mail: lanning@unc.edu) is System Administrator, Academic Affairs Library, Campus Box 3946, University of North Carolina at Chapel Hill, NC 27599-7585.

\footnotetext{
${ }^{7}$ Nelson, Antoinette and Frantz, Pollyanne. (1991), “Accessing Closed Collections: The Librarian Holds the Key." Technical Services Quarterly, 17(1): 32.
} 


\section{Appendix A}

\section{Golden Retriever's Cheat Sheet}

1. Pull requested items from stacks. Insert red space keeper.

2. Insert appropriate colored-flag into requested item(s) refer to Color Code Chart.

3. Write User's Last Name, First Initial on colored-flag.

4. Record Last Name, First Initial on completed request form and file under DONE in Paging Services drawer.

5. Shelve item(s) alphabetically by User's Name onto shelves reserved for Paging Items.

\section{Problems}

1. When you see these in the problem folder, please follow up by letting the patron know there may be a delay (canned messages are linked to the USC Intranet in the Esoteric Information section).

2. If it is a duplicate request, do what you think best. For example, try to contact the first patron to get page numbers (journal), or PID (book), and then make photocopy, put in envelope with last name, first initial and put on paging shelf (journal); or check out item, put on hold shelf, put hold on for next requester (book). Then notify both patrons how they can find or ask for the item, it's on hold for them, etc.

3. This does not come up often enough for us to give everyone instructions on handling these problems. Example: We've had 1 duplicate in 100 requests.

As always, if you have a better way, do it. We just want to be sure patrons clearly know what's happening with their request and save them wasting a trip to the library.

\section{Appendix B}

\section{Color Code Chart}

\begin{tabular}{|l|l|l|}
\hline Day of Week & Insert Flag Color & Reshelve This Color \\
\hline Monday & White & Green/Friday \\
\hline Tuesday & Yellow & Blue/Saturday \\
\hline Wednesday & Orange & Purple/Sunday \\
\hline Thursday & Red/Pink & White/Monday \\
\hline Friday & Green & Yellow/Tuesday \\
\hline Saturday & Blue & Orange/Wednesday \\
\hline Sunday & Purple & Red/Pink/Thursday \\
\hline
\end{tabular}

Explanation: 3 day hold period, re-shelve items on 4th day.

Example: If it's Thursday: Re-shelve Monday items/White flag. 


\section{Appendix C}

While materials are being moved, request journal volumes from the Health Sciences Library's collection using this form.

TIPS:

SAVE TIME: Look in the UNC Libraries Catalog for your journal. If the item is listed as Checked out, you will need to use the IRIS Request form.

ARTICLE ONLINE? Is your article available online in full text? Please look up the title of the journal in the campus E-Journals list.

2004 ARTICLE? If the journal issue is marked "arrived" in our Current Journals @ HSL, you can retrieve it on your own on the first floor in the current journals collection.

TURNAROUND: Items will be ready for you to pick up or copy by noon of next business day. Weekend requests will be ready by Monday at $4 \mathrm{pm}$. You will be notified only if there is a problem with a request you have submitted.

\section{MORE INFO}

Request Form:

ALL FIELDS ARE REQUIRED FOR THE FORM TO BE PROCESSED!

Personal Information:

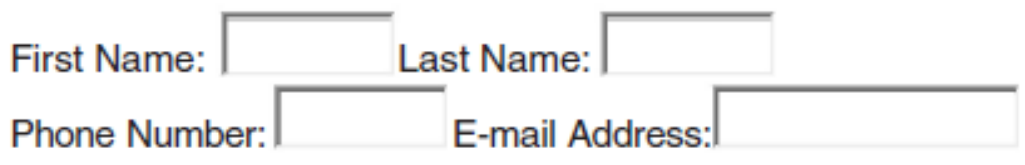

Journal Information:

Journal Title:

Year: $\quad$ [YYYY] Volume: $\square$ Issue/Month:

Submit Request: Clear Form

While materials are being moved, request books from the Health Sciences Library's collection using this form.

TIPS:

SAVE TIME: Look in the UNC Libraries Catalog for your book's call number. Enter it below. If the item is listed as Checked out, you will need to use the IRIS Request form. 
BEFORE 1992? Books with publication years earlier than 1992 are in storage for a few more weeks. For now, please continue to request these using the IRIS form.

TURNAROUND: Items will be ready for you to pick up or copy by noon of next business day. Weekend requests will be ready by Monday at $4 \mathrm{pm}$. You will be notified only if there is a problem with a request you have submitted.

MORE INFO

Request Form:

ALL FIELDS ARE REQUIRED FOR THE FORM TO BE PROCESSED!

Personal Information:

First Name: $\quad$ Last Name:

Phone Number: $\quad$ E-mail Address:

\section{Book Information:}

Book Title:

Author:

Call Number:

Publication Year:

[YYYY]

\begin{tabular}{l|l} 
Submit Request: & Clear Form
\end{tabular} 